\title{
STUDY OF OXIDATIVE STRESS AND ENZYMATIC ANTIOXIDANTS IN NORMAL PREGNANCY
}

\author{
S.B. Patil., M.V. Kodliwadmath, Sheela M. Kodliwadmath ${ }^{*}$
}

Dept. of Biochemistry and "Dept of Obstetrics and gynecology, J.N. Medical College, Nehru Nagar, Belgaum-10

\begin{abstract}
Pregnancy is a physiological state accompanied by a high-energy demand and an increased oxygen requirement. Augmented levels of oxidative stress would be expected because of the increased intake and utilization of oxygen. Evidence of increased oxidative stress in normal pregnancy in comparison with nonpregnant controls was estimated by measuring Thiobarbituric acid reactive substance (TBARS), enzymatic antioxidants like Superoxide dismutase, Glutathione peroxidase, Glutathione reductase and catalase. It was observed that pregnant women were more susceptible to oxidative damage than non-pregnants as indicated by increased TBARS and decreased antioxidants.
\end{abstract}

\section{KEY WORDS}

Lipid peroxidation, Malondialdehyde, Thiobarbituric acid, Superoxides.

\section{INTRODUCTION}

Pregnancy is a stressful condition in which many physiological and metabolic functions are altered to a considerable extent (1). Now a days lipid peroxidation has become an acceptable trend in medicine to consider at molecular level. Vascular endothelial dysfunction may be caused by uncontrolled lipid peroxidation (2). Lipid peroxidation is an oxidative process which occurs at low levels in all cells and tissues (3). Under normal conditions a variety of antioxidant mechanisms serve to control this peroxidative process (4).

In recent years the role of decreasing antioxidants and increasing superoxides is gaining importance as they are threat for the normal pregnancy. Certain biochemical indices are useful in assessing the progression of pregnancy. Hence the present study was undertaken to assess the role of antioxidants, lipid peroxidation and superoxide generation in normal pregnancy.

The generation of free radical is a normal physiological process but increased production of free radicals can act on lipids to

\section{Address for Correspondence:}

Dr. S.B.Patil.

Assistant Professor, Dept.of Biochemistry

Jawaharlal Nehru Medical College

Nehru Nagar, Belgaum-590010. Karnataka. (India).

E-mail : sanrum03@yahoo.co.in cause lipid peroxidation (5) The cells have evolved a number of counter acting antioxidant defenses. These antioxidant defense mechanisms can be categorized in to two types- free radical scavenging and chain breaking antioxidants. The free radical scavenging mechanisms include enzymatic antioxidant like Superoxide dismutase (SOD), Glutathione peroxidase (GSH-Px), Glutathione reductase (GSH-Rx) and Catalase, which limit the cellular concentration of free radicals and prevent excessive oxidative damage (1).

The aim of the present study is to assess the lipid peroxidation and enzymatic antioxidant activities in the normal pregnant women (ISt II $^{\text {nd }}$ and III ${ }^{\text {rd }}$ trimesters) as compared to nonpregnant women.

\section{MATERIALS AND METHODS}

The present study comprises of 75 normal pregnant women (25 in each trimester) attending for antenatal checkup at District civil hospital, Belgaum and 25 healthy non-pregnant women as controls ranging in age from $20-40$ years. The subjects were from low socio economic status as they had low-income. The subjects with obesity, Diabetes mellitus under medication and untreated diabetes, Alcoholic, Severely anaemic $(<6.0$ $\mathrm{gm} \%$ of $\mathrm{Hb}$ ) and those Suffering from any other systemic disorder were excluded from the study.

Analysis of variance followed by bornferroni multiple 
Table 1 : Malondialdehyde and enzymatic antioxidant levels in the non-pregnant and normal pregnant women (Ist, II ${ }^{\text {nd }}$ and III ${ }^{\text {rd }}$ trimester).

\begin{tabular}{l|c|c|c|c|c}
\hline & $\begin{array}{c}\text { MDA } \\
\mathrm{n} \mathrm{mol} / \mathrm{ml}\end{array}$ & $\begin{array}{c}\text { SOD } \\
\text { IU/gm Hb }\end{array}$ & $\begin{array}{c}\text { GSH-Px } \\
\text { IU/gm Hb }\end{array}$ & $\begin{array}{c}\text { GSH-Rx } \\
\text { IU/gm Hb }\end{array}$ & $\begin{array}{c}\text { CATALASE } \\
\text { IU/gm Hb }\end{array}$ \\
\hline Non-pregnant $\mathbf{n = 2 5}$ & $1.19 \pm 0.09$ & $683.99 \pm 155.25$ & $31.08 \pm 4.54$ & $10.52 \pm 4.67$ & $8.13 \pm 2.25$ \\
Pregnant $\mathbf{n = 7 5}$ & $1.42 \pm 0.13$ & $617.10 \pm 134.35$ & $28.29 \pm 5.06$ & $10.17 \pm 3.49$ & $7.82 \pm 2.84$ \\
Ist Trimester. $\mathrm{n}=25$ & $1.64 \pm 0.12$ & $584.24 \pm 131.01$ & $26.14 \pm 5.98$ & $9.19 \pm 2.77$ & $7.0 \pm 2.33$ \\
IInd Trimester $\mathrm{n}=25$ & $1.79 \pm 0.14$ & $542.64 \pm 142.86$ & $23.45 \pm 4.89$ & $7.78 \pm 3.47$ & $6.20 \pm 1.73$ \\
IIIrd Trimester $\mathrm{n}=25$ & $\mathrm{~F}-116.882$ & $\mathrm{~F}-4.469$ & $\mathrm{~F}-9.884$ & $\mathrm{~F}-2.810$ & $\mathrm{~F}-3.494$ \\
& $\mathrm{p}<0.000$ & $\mathrm{p}<0.006$ & $\mathrm{p}<0.000$ & $\mathrm{p}<0.044$ & $\mathrm{p}-0.019$ \\
& & & & &
\end{tabular}

comparison test was used for statistical evaluation.

$10 \mathrm{ml}$ of blood was drawn by venipuncture and collected in a heparinized tube (10 units $/ \mathrm{ml}$ of blood). The following parameters were analyzed within 10-15 minutes of collecting blood sample. Superoxide dismutase (7), Glutathione peroxidase, Glutathione reductase and Catalase (8). Malondialdehyde (MDA) as Thiobarbituric acid reactive substance (6).

\section{RESULTS \& DISCUSSION}

In present study MDA level was found to be significantly increased in pregnant women as compared to control. This increase was gradual with the progression of pregnancy from $1^{\text {st }}$ to III ${ }^{\text {rd }}$ trimester, while antioxidants SOD, GSHPx, GSHRx and catalase were found to be lowest in $\mathrm{III}^{\text {rd }}$ trimester of pregnancy.

Free radicals by their unstable and transient nature are difficult to measure directly. Their tendency to cause lipid peroxidation has been used as an indirect measure. Markers of lipid peroxidation (MDA) have been increased during the progression of normal pregnancy (9). Ishihara (10) studied, lipid peroxide levels in non-pregnant and normal pregnant $\left(\mathrm{I}^{\mathrm{st}}\right.$, $\mathrm{II}^{\text {nd }}$ and $\mathrm{II}^{\text {rd }}$ trimesters) and reported remarkable increased levels of lipoperoxides in $\mathrm{II}^{\mathrm{nd}}$ and $\mathrm{III}^{\text {rd }}$ trimesters of pregnancy as compared to non-pregnant women. Similar observation was made by Kodliwadmath et al (11). In the present study, it was found that there is significant increase of lipid peroxides in all the three trimesters.

Since RBC have no nucleus, increased oxidative stress causes induction of antioxidant enzyme activities and this increase suggests a role of superoxide dismutase in the protection of embryonic development against free radical damage, which was observed by Carone et al (12). But, Stephen Wisdom et al (13) and Davidge et al (14) found that there is reduced superoxide dismutase activity in the third trimester of normal pregnancy as compared to non-pregnant women. Behne (15) and Pathak et al (16) have shown that there is a progressive fall in the activity of plasma Glutathione peroxidase and superoxide dismutase as pregnancy advanced. Our study reveals similar findings, but the decrease of both superoxide dismutase and Glutathione peroxidase were statistically significant.

$\mathrm{Yu}$ (17) suggested that reduced glutathione is an effective reductant and plays an important role in a variety of detoxification processes. The enzyme Glutathione reductase plays a pivotal role in replenishing and maintaining optimum concentrations of reduced glutathione in biological systems. A gradual decrease in the activities of glutathione reductase and catalase throughout the three trimesters of pregnancy were observed in our study.

\section{REFERENCES}

1. Scott, Walsh. Lipid Peroxidation in Pregnancy. Hypertension in Pregnancy 1994; 13(1): 1-32.

2. Hubel CA, James M and Robert MD, Robert N, Taylor MD, Thomas J, et al. Lipid peroxidation in pregnancy: New perspectives on pre-eclampsia. Am J Obstet Gynecol 1989; 161: 1025-34.

3. Kagan VE. Lipid peroxidation in biomembrane. Boca Raton Florida: CRC Press, 1988: 131pp.

4. Sies H. Oxidative stress: Oxidants and antioxidants. Am J Med 1991; 91: 3C.

5. Cheesman $\mathrm{KH}$, Slater TF. An introduction to free radical biochemistry Br Medical . Bulletin 1993; 49(3): 481-493.

6. Arch. Biochem. Biophysics 1982; 216: $204-212$. 
7. Misra HP, Fridovich I. The role of superoxide anion in the auto oxidation of epinephrine and a simple assay for superoxide dismutase. J Biol Chem 1972; 247: 3170-75.

8. Beutler E. Red cell metabolism- A manual of biochemical methods, Vol. 16. London: Edinburgh Churchill Livingstone Publication, 1986.

9. Wickens D. Oxidation (peroxidation) products in plasma in normal and abnormal pregnancy. Ann Clin Biochem 1981; 18: $158-62$.

10. Ishihara M. Studies on lipoperoxide of normal pregnant women and of patients with toxemia of pregnancy. Clin Chim Acta 1978; 84: 1-9.

11. Kodliwadmath SM, Sadashivadu B. and Kodliwadmath MV. Serum Malondialdehyde and ceruloplasmin Levels in toxaemia of pregnancy. $\mathrm{J}$ of Obstetrics and Gynecology of India 1989; 5: 648-51.

12. Carone D, Loverro, Gereco P, Capuano F. Lipid peroxidation products and antioxidant enzymes in red blood cells during normal and diabetic pregnancy. Eur J Obstet Gyneccol Repro Biol 1993; 51: 103-9.
13. Stephen, Wisdom, Wilson R, Mc Killop H. Antioxidant systems in normal pregnancy and in pregnancy induced hypertension. Am J Obstet Gyncecol 1991; 165: 1701-4.

14. Davidge ST, Hubel CA, Brayden RN, Capeless EC, Mc Laughlin MK. Sera antioxidant activity in uncomplicated and pre-eclamptic pregnancies. Obstetrics and Gynecology 1992; 79(6): 897-901.

15. Behne D, Wolters W. Selenium content and glutathione peroxidase activity in the plasma and erythrocytes of nonpregnant and pregnant women. J Clin chem Clin Biochem 1979; 17: 133-5.

16. Pathak SS, Shetty DN. Essentially Zinc in pregnancy to maintain antioxidant status. The Indian Practitioner 2001; 54(11): 766-70.

17. Yu BP. Cellular defenses against damage from reactive oxygen species. Phy Rev 1994; 74(1): 139-62. 